\title{
Pearce, D. (2012). Frameworks for Tourism Research. CABI. ISBN 978-1-84593-898-7, 210 pp.
}

\author{
Reviewed by Craig Webster ${ }^{1}$
}

Received: 07/02/2013

\begin{abstract}
1 Department of European Studies and International Relations, University of Nicosia, 46 Makedonitissas Avenue, 1700 Nicosia, Cyprus; tel.: +357 22841500; e-mail: webster.c@unic.ac.cy
\end{abstract}

(C) 2013 International University College. All rights reserved

Citation: Pearce, D. (2012). Frameworks for Tourism Research. CABI. ISBN 978-1-84593-898-7, 210 pp., Reviewed by Craig Webster, European Journal of Tourism Research 6(1), 95-97.

It is a pleasure for me to review "Frameworks for Tourism Research." In this book Douglas Pearce writes in detail about what seems to be a catchphrase ("framework") in academic circles that all are expected to understand and appreciate. The strength of this work is that it deals in depth with the concept of frameworks, defining them and illustrating how they are used and can be used in the academic study of tourism. The author writes in detail on this thing that most of us give only the most superficial amount of attention to and makes us aware of its importance and application.

The book is divided into ten chapters. What is most remarkable about the book is the number of figures it contains (71), although there are only four tables. The amount of visual information is a benefit to the book, as it supports the prose, this is especially attractive to people such as myself who enjoy the visual display of information.

The first chapter is an interesting discussion of what is meant by frameworks, the central theme of the entire book. In this chapter the author discusses the definition of frameworks and the delineation between frameworks and related concepts such as models and theories. He then follows up on this with a discussion of BOOK REVIEW the definition of "conceptual frameworks," "analytical frameworks," and "integrative frameworks." He also explains the logic of the structure of the rest of the chapters in the book.

In the second chapter, the author focuses upon theoretical frameworks and discusses their utility in doing research. In this chapter, there is a detailed discussion of frameworks and the different levels of frameworks, as well as examples of the application of frameworks. Indeed, this is a strong chapter, explaining not only more precisely what is meant by a "framework" but illustrating different applications of frameworks as well as the implications of using frameworks.

The third chapter focuses upon conceptual frameworks. In this chapter, the author explains what is meant by "conceptual frameworks" and he illustrates the value of such frameworks with a discussion of them as well as the use of various examples of such frameworks as they have been used in tourism research. What is noteworthy about this chapter is that it is packed with visual information (ten figures and two tables). The fourth chapter deals with analytical frameworks and is another chapter filled with visual information (ten figures and one table). It illustrates what is meant by an 
analytical framework and illustrates the many different ways in which such frameworks can be and have been utilized in tourism research.

The fifth chapter deals with what the author refers to as "integrative frameworks." $\mathrm{He}$ illustrates what is meant by "integrative frameworks" by illustrating via various examples different integrative frameworks used in the field of tourism research. The sixth chapter focuses upon multi-purpose matrices. As with the other chapters, the author explains how matrices are used in tourism research and gives a number of examples to illustrate how they have been used, illustrating the value of these approaches in research and the historical application of these approaches in tourism research.

The seventh chapter deals with process frameworks, illustrating how different approaches to processes in tourism can be analysed. This is an intriguing chapter, looking at processes and evolution over time to look at how tourism develops or has developed in various places. The eighth chapter ("systems, networks, and composite frameworks") focuses upon more sophisticated frameworks. This chapter is engaging and illustrates how frameworks such as systems analysis and network analysis have been used in analyzing tourism.

In Chapter Nine, the author deals with issues regarding the choice of frameworks available to researchers and the decision about which framework to use. The tenth chapter is the concluding chapter, focusing upon frameworks and the future directions of frameworks in tourism research.

In terms of the style/writing of the book, I find it easy to read. For me, the autobiographic information in the first chapter leading to how the author came to write the book and his interest in frameworks was not really necessary, although some may appreciate an explanation for how a veteran in the field of tourism research came to be interested in the topic. One thing that I really appreciate is that the many figures and tables allow the reader to comprehend the frameworks and their applications in tourism in a visual manner, rather than via prose alone. I can imagine that it was a great deal of trouble to get the permission from various sources to use the figures and tables and this is something that readers should appreciate. Without the many figures, the book would have had much less appeal.

The topic of the book is relevant, interesting, and useful. Although it is probably not the type of book that a person would read for fun, it would be a great asset to have in a library for those who engage in serious research in the field of tourism. For me, the book works like a very long and sophisticated literature review on the topic of frameworks. As a long and sophisticated literature review, it has a great deal of value. I expect that many will see that the great deal of trouble that the author has gone to to delineate between different categories of frameworks and illustrate how these different categories have been implemented in research on tourism will be worth something, either as a teaching tool or in assisting in doing research.

My suspicion is that advanced undergraduates or graduate/post-graduate students could get a great deal out of this book. Although I suspect that the abstraction of dealing with epistemological issues may be beyond the scope of the ability of most undergraduates, the book would be of a great deal of use to first year graduate/post-graduate students, probably not as a major text but certainly as a good supporting/recommended text for a methodology class. If I were teaching a methodology class, I could envision putting this on the reading list and making sure that it is in the reserve section of the library available to my students. It would be tempting for me to make frameworks a topic of discussion for a three hour teaching session/discussion and use the first two chapters as background material, if I were teaching a class on research methods or epistemology at the graduate/postgraduate level. For researchers, I am sure that this would be a useful reference material, in order to stimulate thinking when beginning a new 
project or when looking for guidance to place a piece of research into a larger framework.

In conclusion, I find this book to be a useful and interesting book for college/university students and for researchers. In particular, I feel that the first two chapters would be a good to reference for advanced undergraduate students or beginning postgraduate/graduate students. The value of these two first chapters are exceptional, as they explicitly deal with models, theories, and framework and define what is meant by these things, rather than just skipping a discussion of what are meant by these things and allowing students to figure out what is meant by these words on their own. 